\title{
Intestinal colonization due to Escherichia coli ST131: risk factors and prevalence
}

Isabel Morales Barroso ${ }^{1,2,3^{*}}$, Lorena López-Cerero 1,2, María Dolores Navarro ${ }^{1,2}$, Belén Gutiérrez-Gutiérrez ${ }^{1,2}$, Alvaro Pascual ${ }^{1,2}$ and Jesús Rodríguez-Baño ${ }^{1,2}$

\begin{abstract}
Background: Escherichia coli sequence type 131 (ST131) is a successful clonal group that has dramatically spread during the last decades and is considered an important driver for the rapid increase of quinolone resistance in E. coli.

Methods: Risk factors for rectal colonization by ST131 Escherichia coli (irrespective of ESBL production) were investigated in 64 household members (18 were colonized) and 54 hospital contacts (HC; 10 colonized) of 34 and 30 index patients with community and nosocomial infection due to these organisms, respectively, using multilevel analysis with a $p$ limit of $<0.1$.

Result: Colonization among household members was associated with the use of proton-pump inhibitors (PPI) by the household member $(\mathrm{OR}=3.08$; $95 \% \mathrm{Cl}: 0.88-10.8)$ and higher age of index patients $(\mathrm{OR}=1.05 ; 95 \% \mathrm{Cl} ; 1.01-1.10)$, and among $\mathrm{HC}$, with being bed-ridden ( $\mathrm{OR}=21.1 ; 95 \% \mathrm{Cl}$ : 3.61-160.0) and having a urinary catheter ( $\mathrm{OR}=8.4 ; 95 \% \mathrm{Cl}: 0.87-76.9)$.

Conclusion: Use of PPI and variables associated with higher need of person-to-person contact are associated with increased risk of rectal colonization by ST131. These results should be considered for infection control purposes.
\end{abstract}

Keywords: Escherichia coli, ST131, Intestinal colonisation, Risk factors, Carriage, Prevalence colonization, Outcome

\section{Introduction}

Escherichia coli is among the most frequent cause of bacterial infection in humans, particularly in the urinary and digestive tracts. Therefore, antimicrobial resistance in E. coli has important consequences for antibiotic use. E. coli sequence type 131 (ST131) is a successful clonal group that has dramatically spread during the last decades, and is considered an important driver for the rapid increase in antimicrobial resistance in $E$. coli to quinolones; also some lineages of this clone, such us H30Rx clade $\mathrm{C} 2$, have been linked to the dissemination of the extended-spectrum $\beta$-lactamases (ESBL) CTX-M-15 and CTX-M-14 [1-3]. Importantly, these isolates usually exhibit the virulence factors associated with extraintestinal pathogenic E. coli strains [1]. Therefore, ST131 is important because of its combination of successful spread, antibiotic resistance and virulence.

* Correspondence: imoralesjerez@hotmail.com

1 Unidad Clínica de Enfermedades Infecciosas y Microbiología, Hospital

Universitario Virgen Macarena, Seville, Spain

${ }^{2}$ Departamentos de Medicina y Microbiología, Universidad de Sevilla / CSIC/

Instituto de Biomedicina de Sevilla, Seville, Spain

Full list of author information is available at the end of the article
Most epidemiological studies on intestinal colonisation by ST131 has been performed on isolates producing ESBLs. However, most ST131 isolated from rectal [4] or clinical samples [5] do not produce ESBLs. Thus, investigating the epidemiology of ST131 is challenging because these isolates lack a specific susceptibility marker, so that molecular methods must be applied to a high number of E. coli isolates in order to identify those belonging to ST131 clonal group. This is complex for prospective studies. Therefore, our knowledge about risk factors for the acquisition of non-ESBL-producing ST131 is very limited but would be relevant from an infection control perspective. The objectives of this study were to investigate the risk factor for colonization among contacts of patients infected with ST131 E. coli irrespective of ESBL production, in the community and hospitals.

\section{Methods}

The risk factors for colonisation with ST131 E. coli were studied using a case-control design in 34 community and 30 hospital clusters, conducted at Hospital Universitario Virgen Macarena, a tertiary hospital attending

(c) The Author(s). 2018 Open Access This article is distributed under the terms of the Creative Commons Attribution 4.0 International License (http://creativecommons.org/licenses/by/4.0/), which permits unrestricted use, distribution, and reproduction in any medium, provided you give appropriate credit to the original author(s) and the source, provide a link to the Creative Commons license, and indicate if changes were made. The Creative Commons Public Domain Dedication waiver (http://creativecommons.org/publicdomain/zero/1.0/) applies to the data made available in this article, unless otherwise stated. 
550.000 population in Seville, Spain, from April 2012 to April 2013. The study design was previously reported [6]. Briefly, the clusters were identified from an "index patient" suffering an infection due to ST131 E. coli (detected by PCR for $O 25 b r f b 4$, allele 3 of the $p a b B$ gene and for the $\mathrm{B} 2_{3}$ phylogroup), and was formed by his/her contacts. Community index patients $(n=34)$ were attending the emergency department and had not been admitted to the hospital during the previous month, and nosocomial index patients $(n=30)$ were hospitalized for $>48 \mathrm{~h}$ when the sample was obtained. The household members of each index community index patients $(n=64$; median per index patient, 2; range 1-4) formed the community clusters, and the patients admitted to the same or nearest rooms and attended by the same team of nurses as the nosocomial index patient ( $n=54$; median, 2; range, $1-6$ ) formed the nosocomial clusters. Rectal colonisation by ST131 E. coli was studied in all participants by performing rectal swabs within one week of index case detection, and 1 and 3 months later.

The microbiological procedures were previously reported [4]; in summary, rectal swabs were inoculated to Brilliance UTI agar, MacConkey agar containing $4 \mathrm{mg} / \mathrm{L}$ cefotaxime and a blood agar plate; all distinct $E$. coli morphotypes were screened for O25b/pabB3/B23. ESBL production was studied in all third-generation cephalosporin-resistant isolates by the double-disk synergy test. Antibiotic susceptibility was studied by broth microdilution according to Clinical and Laboratory Standards Institute (CLSI) recommendations [7].

As previously reported, $18 / 64$ (28.1\%) household members from $13 / 34$ (38.2\%) community clusters and $8 / 54$ (14.8\%) contacts from 8/30 (26.6\%) nosocomial clusters were colonized by ST131 E. coli in at least one of the 3 rectal swabs performed [4] (Fig. 1). Data were collected by personal interviews using a predesign questionnaire with the variables showed in Tables 1 and 2, before any information about colonization status was known. To consider both the individual and cluster levels of exposure to risk factors for colonisation with ST131 E. coli, the variance among patients in the clusters were the risk factors for colonisation with ST131 E. coli in any of the 3 rectal swabs were investigated using a multilevel logistic regression analysis if the variance among patients in the clusters was significant ( $P$ value by Wald test $\leq 0.2$ ); in that case, a two-level logistic regression analysis (level 1 was formed by the individual participants and level 2 by clusters) was performed. If $p$ value by Wald test was $>0.2$, a conditional logistic regression was performed for level 1 . Variables were kept in the models if their $p$ values were $<0.1$. Mlwin 3.0 (University of Bristol, UK) and SPSS 21.0 (IBM Corp, Armonk, New York, USA) were used for the analyses. The Institutional Review Board of the Hospital Universitario Virgen Macarena approved the study.

\section{Results}

The distribution of participants according to colonization status and clusters is shown in Fig. 1. The univariate comparison in exposure to potential risk factors between the 18 colonized and 46 non-colonized participants from community clusters, and between community clusters with and without colonized member (13 and 21, respectively) are shown in Table 1 . The variables with a $p$ value $<$ 0.2 for their association to colonization were higher age, being dependant for basic activities, not sharing bathroom with index case, recent antibiotic use and proton pump inhibitors (PPI) use in the individual level, and age of the index patient in the cluster level. The $\mathrm{p}$ value for the variance at the cluster level was 0.20 ; therefore, a multilevel analysis was performed; the variables associated with ST131 colonisation were PPI use in the individual level and age of the index patient in the cluster level (Table 1).

The univariate comparison in exposure to potential risk factors between the 10 colonized and 44 non-colonized participants from nosocomial clusters, and between nosocomial clusters with and without a colonized member $(8$

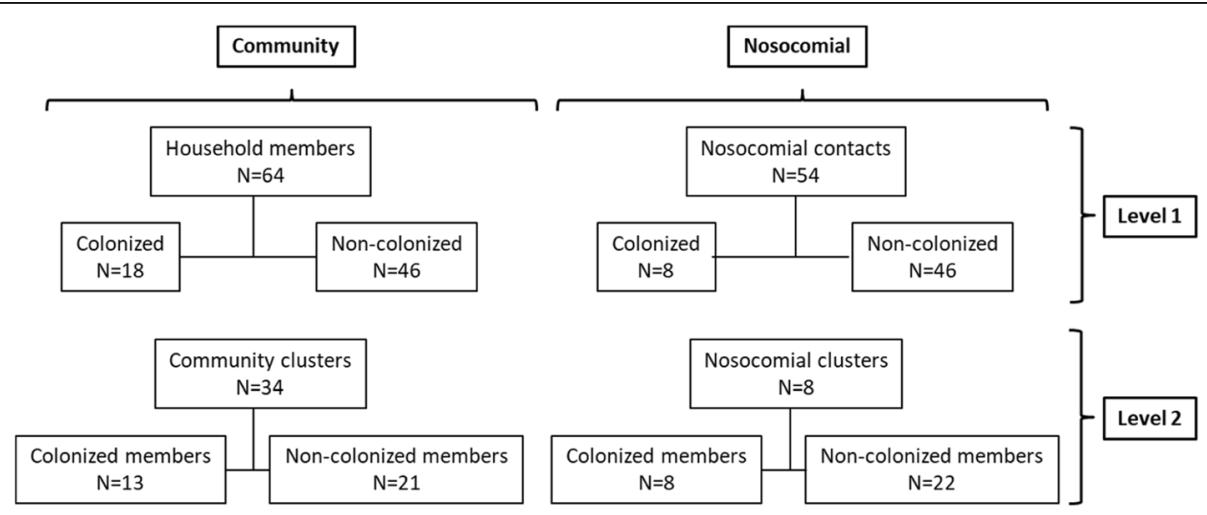

Fig. 1 Distribution of participants 
Table 1 Characteristics of ST131 E. coli colonized and non-colonized household members of index community patients. Data are expressed as number of exposed patients (percentage) except where specified

\begin{tabular}{|c|c|c|c|c|c|}
\hline $\begin{array}{l}\text { Features of contacts } \\
\text { (individual level) }\end{array}$ & $\begin{array}{l}\text { ST } 131 \text { colonized household } \\
\text { members }(n=18)\end{array}$ & $\begin{array}{l}\text { Non-ST131 colonized household } \\
\text { members }(n=46)\end{array}$ & $P$ & $\begin{array}{l}\text { Adjusted OR } \\
\text { (multilevel) }\end{array}$ & $p$ \\
\hline Median age in years (IQR) & $55(47.25-74)$ & $48(37-58.5)$ & 0.06 & & \\
\hline Male gender & $6(33.3)$ & $17(37.0)$ & 0.78 & & \\
\hline Median Charlson index (IQR) & $0(0-0)$ & $0(0-0)$ & 0.42 & & \\
\hline Diabetes mellitus & $2(11.1)$ & $3(6.5)$ & 0.61 & & \\
\hline Cancer & 0 & $3(6.5)$ & 0.55 & & \\
\hline Recurrent urinary tract infections & $1(5.6)$ & 0 & 0.28 & & \\
\hline Dependent for basic activities & $2(11.1)$ & 0 & 0.07 & & \\
\hline Bed-ridden & $1(5.6)$ & 0 & 0.28 & & \\
\hline Recurrent urinary tract infections & $1(5.6)$ & 0 & 0.22 & & \\
\hline Urinary catheter & 0 & 0 & & & \\
\hline Usual caregiver of index patient & $11(61.1)$ & $21(45.6)$ & 0.26 & & \\
\hline Contact with farm animals & $1(5.6)$ & $1(2.2)$ & 0.48 & & \\
\hline Shared bathroom with index patient & $14(77.8)$ & $42(91.3)$ & 0.14 & & \\
\hline Travel abroad in the previous 3 months & 0 & $1(2.2)$ & 1 & & \\
\hline Sexual partner of index patient & $6(33.3)$ & $14(30.4)$ & 0.82 & & \\
\hline Mean meal outside home $>3$ days/week & $3(16.7)$ & $6(13.0)$ & 0.70 & & \\
\hline Cook regularly at home & $9(50)$ & $22(47.8)$ & 0.87 & & \\
\hline Eat chicken products $\geq 1$ per week & $11(61.1)$ & $28(60.9)$ & 0.98 & & \\
\hline Eat turkey products $\geq 1$ per week & $5(27.8)$ & $17(37.0)$ & 0.48 & & \\
\hline Eat raw vegetables $\geq 1$ per week & $17(94.4)$ & $39(84.8)$ & 0.29 & & \\
\hline Recent antibiotic use & $3(16.7)$ & $1(2.2)$ & 0.06 & & \\
\hline Proton pump inhibitor use & $9(50.0)$ & $12(26.1)$ & 0.06 & $3.08(0.88-10.8)$ & 0.07 \\
\hline $\begin{array}{l}\text { Features of index patient } \\
\text { (cluster level) }\end{array}$ & $\begin{array}{l}\text { Clusters with one or more ST131 } \\
\text { colonized household member }(n=13)\end{array}$ & $\begin{array}{l}\text { Clusters without any ST131 colonized } \\
\text { household member }(n=21)\end{array}$ & $P$ & & \\
\hline Median age in years (IQR) & $79(69.75-83.75)$ & $67.5(51.5-81)$ & 0.16 & $1.05(1.01-1.10)$ & 0.05 \\
\hline Male gender & $8(61.5)$ & $8(38)$ & 0.43 & & \\
\hline Bed-ridden & 0 & 0 & 0.81 & & \\
\hline Dependent for basic activities & $2(15.3)$ & $2(9.5)$ & 0.65 & & \\
\hline Urinary catheter & $4(30.7)$ & $3(14.28)$ & 0.36 & & \\
\hline Median Charlson index (IQR) & $0.5(0-2)$ & $1.5(0-2)$ & 1 & & \\
\hline Pets at home & $7(53.8)$ & $11(52.4)$ & 0.96 & & \\
\hline Recent antimicrobial use & $9(69.2)$ & $13(61.9)$ & 0.84 & & \\
\hline
\end{tabular}

and 22, respectively) are shown in Table 2. The variables with a $p$ value $<0.2$ for their association to colonization in the individual level were age, being dependant for basic activities or bed-ridden and having a urinary catheter; no variable showed was selected in the cluster level. The $\mathrm{p}$ value for the variance at the cluster level was 0.95 ; therefore, multilevel analysis was not performed; the variables associated with colonisation in the multivariate conditional logistic regression were being dependent for activities and urinary catheter (Table 2).

The susceptibility of ST131 isolates is shown in Table 3. Overall, 6 isolates (21.4\%) were ESBL-producers.

\section{Discussion}

Despite the obvious limitation related to low numbers, we were able to identify some risk factors for rectal colonisation by ST131 in community and nosocomial clusters of patients with infection due to these organisms. PPI use and higher age in the index patients are associated with intestinal colonisation with ST131 among household members of patients with previous community-acquired infection due to this organism; this is interesting as PPI use has been found also to be a risk factor for colonisation with ESBL-producers [8] and other enteric pathogens. This might be related to the fact that PPI eliminate the 
Table 2 Characteristics of ST131 E. coli colonized and non-colonized hospital contacts of index nosocomial patients. Data are expressed as number of exposed patients (percentage) except where specified

\begin{tabular}{|c|c|c|c|c|c|}
\hline $\begin{array}{l}\text { Features of contacts } \\
\text { (individual level) }\end{array}$ & $\begin{array}{l}\text { ST } 131 \text { colonized hospital } \\
\text { contacts }(n=10)\end{array}$ & $\begin{array}{l}\text { Non-ST131 colonized hospital } \\
\text { contacts }(n=44)\end{array}$ & $P$ & Adjusted OR & $p$ \\
\hline Median age in years (IQR) & $81.5(75.5-87.75)$ & $6.08(59.75-80.0)$ & 0.05 & & \\
\hline Male gender & $5(50.0)$ & $20(45.4)$ & 0.79 & & \\
\hline Median Charlson index (IQR) & $1(0.25-5)$ & $1(0-3.75)$ & 0.76 & & \\
\hline Diabetes mellitus & $3(30.0)$ & $15(34.0)$ & 0.80 & & \\
\hline Cancer & $3(30.0)$ & $13(29.5)$ & 0.98 & & \\
\hline Liver cirrosis & 0 & $1(2.2)$ & 1 & & \\
\hline Recurrent urinary tract infections & $1(10.0)$ & $1(2.2)$ & 0.34 & & \\
\hline Dependent for basic activities & $5(50.0)$ & $3(6.8)$ & 0.003 & $21.1(3.61-160.0)$ & 0.001 \\
\hline Bed-ridden & $1(10.0)$ & 0 & 0.18 & & \\
\hline Shared room with index patient & $7(70.0)$ & $24(54.5)$ & 0.37 & & \\
\hline Surgery during present admission & $4(40.0)$ & $15(34.0)$ & 0.72 & & \\
\hline Urinary catheter & $6(60.0)$ & $12(27.2)$ & 0.19 & $8.4(0.97-76.9)$ & 0.05 \\
\hline Recent antimicrobial use & $4(40.0)$ & $16(36.3)$ & 0.83 & & \\
\hline Proton pump inhibitor use & $6(60.0)$ & $34(77.2)$ & 0.85 & & \\
\hline $\begin{array}{l}\text { Median (IQR) days of } \\
\text { hospital stay }\end{array}$ & $5.5(4.0-11.25)$ & $6(3.75-9)$ & 0.70 & & \\
\hline $\begin{array}{l}\text { Features of index patient } \\
\text { (cluster level) }\end{array}$ & $\begin{array}{l}\text { Clusters with at least one ST131 } \\
\text { colonized hospital contact }(n=8)\end{array}$ & $\begin{array}{l}\text { Clusters without any ST131 colonized } \\
\text { hospital contact }(n=22)\end{array}$ & $P$ & & \\
\hline Median age in years (IQR) & $62.50(52.75-78)$ & $67.10(58.25-80.75)$ & 0.70 & & \\
\hline Male gender & $5(62.5)$ & $6(27.3)$ & 0.28 & & \\
\hline Median Charlson index (IQR) & $2.60(0-6)$ & $2.40(0-6)$ & 0.7 & & \\
\hline Bed-ridden & 0 & $3(13.6)$ & 0.53 & & \\
\hline Dependent for basic activities & $2(25)$ & $4(18.1)$ & 0.73 & & \\
\hline Admission to a surgical ward & $4(50)$ & $8(36.3)$ & 0.66 & & \\
\hline Admission to a medical ward & $5(62.5)$ & $11(50)$ & 0.74 & & \\
\hline Admission to an intensive care unit & $1(12.5)$ & 0 & 0.21 & & \\
\hline Surgery during present admission & $4(50)$ & $5(22.7)$ & 0.39 & & \\
\hline Urinary catheter & $7(87.5)$ & $10(45.4)$ & 0.76 & & \\
\hline Recent antimicrobial use & $7(87.5)$ & $10(45.4)$ & 0.42 & & \\
\hline Median (IQR) days of hospital stay & $27.2(7-46)$ & $35.5(14.75-24)$ & 0.59 & & \\
\hline
\end{tabular}

Table 3 Antimicrobial susceptibility of ST131 Escherichia coli isolates. Data are number of susceptible isolates (percentage)

\begin{tabular}{llll}
\hline Antimicrobial & All isolates $(n=28)$ & Isolates from household members $(n=18)$ & Isolates from hospital contacts $(n=10)$ \\
\hline Ampicillin & $6(21.4)$ & $6(33.3)$ & 0 \\
Amoxicillin-clavulanic acid & $9(31.2)$ & $9(50)$ & 0 \\
Piperacillin-tazobactam & $27(96.4)$ & $18(100)$ & $9(90)$ \\
Ceftriaxone & $22(78.5)$ & $15(83.3)$ & $7(70)$ \\
Ceftazidime & $22(78.5)$ & $15(83.3)$ & $7(70)$ \\
Ertapenem & $28(100)$ & $18(100)$ & $10(100)$ \\
Ciprofloxacin & $9(32.1)$ & $6(33.3)$ & $3(30)$ \\
Gentamicin & $24(85.7)$ & $17(94.4)$ & $7(70)$ \\
Tobramycin & $19(67.8)$ & $14(77.8)$ & $5(50)$ \\
Amikacin & $28(100)$ & $18(100)$ & $10(100)$ \\
Fosfomycin & $28(100)$ & $18(100)$ & $10(100)$ \\
\hline
\end{tabular}


barrier that the acid content of the stomach pose to digestive tract colonisation of exogenous bacteria by ingestion. The higher age in index patients may be interpreted as higher need for care and therefore more frequent contact. In hospitals, the risk factors found (dependence for basic activities and urinary catheter) might also be associated with increased need for care and contact. These results suggest that direct contact would be a prominent mechanism of transmission for ST131 and build on the concept that avoiding such direct person-to-person transmission would be critical to reduce the spread of these isolates [9].

The information about risk factors for colonisation with ST131 is scant. While household transmission of ST131 isolates has been well demonstrated $[6,10]$, we could find no studies investigating the risk factors for transmission. In healthcare centers, Han et al. could not identify relevant differences between 29 and 8 long-term care facility (LTCF) residents colonized with ST131 and non-ST131 fluoroquinolone-resistant E. coli. [11]; in another study in a LTCF, Burgess et al. found that time of admission, being unable to sign consent, decubitus ulcer and fecal incontinence were risk factors for colonisation with ciprofloxacin-resistant ST131 E. coli [12]. Other studies only investigated ESBL-producing ST131 isolates $[1,2]$.

Previous antibiotic use was not identified as risk factor in those studies or in the present one; however, we found exposure to antibiotics (specifically amoxicillin-clavulanic acid and fluoroquinolones) to be associated with increased risk of infection due to ST131 [13]. While it may just be a problem of statistical power, antibiotics might be more important in the case of infections by selecting ST131 in the gut of already colonized persons than as a factor clearly favouring colonization.

This study has limitations that should be considered, including a limited statistical power to detect risk factors due to small sample size in relation with the difficulties in performing a study on colonization with bacteria for which no phenotypic marker exists; the sensitivity of detection of ST131 from rectal swabs might be lower than desired; and the results might be applicable only to clusters with an infected person and areas with a similar epidemiology and clades of ST131.

\section{Conclusion}

In conclusion, use of PPI and variables associated with higher need of person-to-person contact are associated with increased risk of rectal colonization by ST131. These results should be considered for infection control purposes.

\section{Abbreviations}

ESBL: extended-spectrum beta-lactamase; LTCF: Iong-term care facility; PPI: proton-pump inhibitors; ST131: Escherichia coli sequence type 131

\section{Acknowledgements}

Funding: The authors receive funds for research from Plan Nacional de I + D + i 2013-2016, Instituto de Salud Carlos III, Subdirección General de Redes y Centros de Investigación Cooperativa, Ministerio de Economía, Industria y Competitividad, Spanish Network for Research in Infectious Diseases, - co-financed by European Development Regional Fund "A way to achieve Europe", Operative Programme Intelligent Growth 2014-2020 (REIPI RD12/0015/0010; REIPI RD16/0016/0001). This project was specifically funded by grants provided by Instituto de Salud Carlos III (grant 070190; grant AC16/000076-MODERN; and grant AC16/AC16/00072-

ST131TS, within the JPI-EC-AMR framework) and Junta de Andalucía (grants CTS5259 and (TS210). The funders had no role in the design, analysis or writing of the manuscript or the decision to publish.

\section{Funding}

The authors receive funds for research from Plan Nacional de I + D + i 2013-2016, Instituto de Salud Carlos III, Subdirección General de Redes y Centros de Investigación Cooperativa, Ministerio de Economía, Industria y Competitividad, Spanish Network for Research in Infectious Diseases, - co-financed by European Development Regional Fund "A way to achieve Europe", Operative Programme Intelligent Growth 2014-2020 (REIPI RD12/0015/0010; REIPI RD16/0016/0001). This project was specifically funded by grants provided by Instituto de Salud Carlos III (grant 070190; grant AC16/000076-MODERN; and grant AC16/AC16/00072ST131TS, within the JPI-EC-AMR framework) and Junta de Andalucía (grants CTS5259 and (TS210).

\section{Availability of data and materials}

The database and isolates are available upon request to authors; a contract with the author's institution is needed before having access to the data.

\section{Authors' contributions}

IMB participated in recruitment of patients, collection and analysis of the data, contributed to the study design and drafted the manuscript. LL-C contributed to the microbiological studies, participated in the data analysis and review the manuscript for scientific content. MDN participated in recruitment of patients, collection of data and review the manuscript for scientific content. BG-G contribute to the study design and data analysis, and reviewed the manuscript for scientific content. AP contributed to the microbiological studies and study design, participated in the data analysis, reviewed the manuscript for scientific content and applied for funds. JR-B designed the study, contributed to the analysis, reviewed the manuscript for scientific content and applied for funds. All authors read and approved the final manuscript.

\section{Ethics approval and consent to participate}

The study was approved by the local institutional review board (Comité Ético del Hospital Universitario Virgen Macarena) and written informed consent was obtained from all participants.

\section{Consent for publication}

Not applicable.

\section{Competing interests}

The authors declare that they have no competing of interests.

\section{Publisher's Note}

Springer Nature remains neutral with regard to jurisdictional claims in published maps and institutional affiliations.

\section{Author details \\ ${ }^{1}$ Unidad Clínica de Enfermedades Infecciosas y Microbiología, Hospital Universitario Virgen Macarena, Seville, Spain. ${ }^{2}$ Departamentos de Medicina y Microbiología, Universidad de Sevilla / CSIC/ Instituto de Biomedicina de Sevilla, Seville, Spain. ${ }^{3}$ Unidad Clínica de Urgencias, Hospital Universitario Virgen Macarena, Seville, Spain.}

Received: 13 August 2018 Accepted: 30 October 2018 Published online: 15 November 2018

\section{References}

1. Nicolas-Chanoine M-H, Bertrand X, Madec J-Y. Escherichia coli ST131, an intriguing clonal group. Clin Microbiol Rev. 2014;27:543-74. 
2. Banerjee R, Johnson JR. A new clone sweeps clean: the enigmatic emergence of Escherichia coli sequence type 131. Antimicrob Agents Chemother. 2014;58:4997-5004.

3. Pitout JDD, DeVinney R. Escherichia coli ST131: a multidrug-resistant clone primed for global domination. F1000Res. 2017;6.

4. Leflon-Guibout V, Blanco J, Amaqdouf K, Mora A, Guize L, Nicolas-Chanoine $\mathrm{MH}$. Absence of CTX-M enzymes but high prevalence of clones, including clone ST131, among fecal Escherichia coli isolates from healthy subjects living in the area of Paris. France J Clin Microbiol. 2008;46:3900-5.

5. López-Cerero L, Bellido Mdel M, Serrano L, Liró J, Cisneros JM, RodríguezBaño J, Pascual A. Escherichia coli O25b:H4/ST131 are prevalent in Spain and are often not associated with ESBL or quinolone resistance. Enferm Infecc Microbiol Clin. 2013;31:385-8.

6. Torres E, López-Cerero L, Morales I, Navarro MD, Rodríguez-Baño J, Pascual A. Prevalence and transmission dynamics of Escherichia coli ST131 among contacts of infected community and hospitalized patients. Clin Microbiol Infect. 2018;24:618-23.

7. Clinical and Laboratory Standard Institute. Methods for dilution antimicrobial susceptibility tests for bacteria that grow aerobically. Approved standard. $8^{\text {th }}$ ed. Wayne, PA: Clinical and Laboratory Standards Institute; 2009. CLSI document M07eA7.

8. Huizinga $\mathrm{P}$, van den Bergh MK, van Rijen M, Willemsen I, Van 't Veer $\mathrm{N}$ Kluytmans J. Proton Pump Inhibitor Use Is Associated With ExtendedSpectrum $\beta$-Lactamase-Producing Enterobacteriaceae Rectal Carriage at Hospital Admission: A Cross-Sectional Study. Clin Infect Dis. 2017;64:361-3.

9. Talaminos A, López-Cerero L, Calvillo J, Pascual A, Roa LM, Rodríguez-Baño J. Modelling the epidemiology of Escherichia coli ST131 and the impact of interventions on the community and healthcare centres. Epidemiol Infect. 2016;144:1974-82.

10. Johnson JR, Davis G, Clabots C, Johnston BD, Porter S, DebRoy C, et al. Household Clustering of Escherichia coli Sequence Type 131 Clinical and Fecal Isolates According to Whole Genome Sequence Analysis. Open Forum Infect Dis. 2016:3:ofw129.

11. Han JH, Garrigan C, Johnston B, Nachamkin I, Clabots C, Bilker WB, et al. Epidemiology and characteristics of Escherichia coli sequence type 131 (ST131) from long-term care facility residents colonized intestinally with fluoroquinolone-resistant Escherichia coli. Diagn Microbiol Infect Dis. 2017; 87:275-80

12. Burgess MJ, Johnson JR, Porter SB, Johnston B, Clabots C, Lahr BD, et al. Long-Term Care Facilities Are Reservoirs for Antimicrobial-Resistant Sequence Type 131 Escherichia coli. Open Forum Infect Dis. 2015;2:ofv011.

13. López-Cerero L, Navarro MD, Bellido M, Martín-Peña A, Viñas L, Cisneros JM, et al. Escherichia coli belonging to the worldwide emerging epidemic clonal group O25b/ST131: risk factors and clinical implications. J Antimicrob Chemother. 2014;69:809-14.

Ready to submit your research? Choose BMC and benefit from:

- fast, convenient online submission

- thorough peer review by experienced researchers in your field

- rapid publication on acceptance

- support for research data, including large and complex data types

- gold Open Access which fosters wider collaboration and increased citations

- maximum visibility for your research: over $100 \mathrm{M}$ website views per year

At $\mathrm{BMC}$, research is always in progress.

Learn more biomedcentral.com/submissions 